\title{
COMPARISON OF NORMAL AND DICHOPTIC COLOUR MIXING ${ }^{1}$
}

\author{
Ch. M. M. DE WeErT and W. J. M. LevelT \\ Psychologisch laboratorium der Katholieke Universiteit, \\ Nijmegen, The Netherlands
}

(Received 9 July 1974; in revised form 3 April 1975)

\begin{abstract}
Dichoptic mixtures of equiluminous components of different wavelengths were matched with a binocularly presented "monocular" mixture of appropriate chosen amounts of the same colour components. Stimuli were chosen from the region of $490-630 \mathrm{~nm}$. Although satisfactory colour matches could be obtained, dichoptic mixtures differed from normal mixtures to a considerable extent. Midspectral stimuli tended to be more dominant in the dichoptic mixtures than either short or long wavelength stimuli. An attempt was made to describe the relation between monocular and dichoptic mixtures with one function containing a wavelength variable and an eye dominance parameter.
\end{abstract}

The existence of dichoptic colour mixing has always been an emotionally laden issue. Terms like "superstitious curiosities" have been used for reports of the occurrence of yellow from red and green in different eyes (Dunlap, 1944). In Das' review (1953) the history of dichoptic colour mixing experiments is given from 1807 (Haldat) to 1953 (Thomas). The issue can best be characterized as a complicated Hering-Helmholtz controversy. On the one hand it relates to their controversy on binocular interaction in general, on the other hand it also entails their controversy on colour vision, centered around the existence of retinal yellow and white detectors. Where in Helmholtz's theory of colour vision dichoptic fusion of red and green into yellow should be easily possible through unconscious judgement, i.e. psychic fusion of the monocularly derived impressions of red and green, he denied this possibility on the base of his own observations, where such mixtures did not occur. This was theoretically understandable according to Helmholtz, since, contrary to the monocular case, slight eye movements would immediately lead to a separation of the two colours so that their identity would be preserved. In Hering's theory of colour vision, dichoptic yellow formation was not easily comprehensible, but his ideas about binocular convergence of the neural pathways from both eyes did not exclude physiological mixing of colour signals in general. Where Hering could obscrve yellow from red and green in different eyes Helmholtz claimed he could not, although he gently admitted that others might be able to do so. For a more detailed survey of dichoptic colour mixture experiments we refer to Das' review.

Solving the problem of dichoptic colour mixing requires at least as much insight into monocular colour vision processes as in binocular interaction in general.

${ }^{1}$ This research was supported by the Dutch Organization for Scientific Research (Z.W.O.), in a grant to the Visual Unit, V7, of the Stichting voor Biofysica.

\section{RELEVANT DEVELOPMENTS IN COLOUR VISION THEORIES}

An important result since Das' review has been the growing agreement upon the existence of three types of photopigments with maximal absorption at about 440,535 and $570 \mathrm{~nm}$. The Hering-Helmholtz controversy has been partly solved by zone theories. All current theories have in common that different channels exist for brightness and colour information, though the way in which different cone types contribute to the different channels is still a matter of controversy for the various models (Walraven, 1962; Hassenstein, 1968; Bouman, 1969; Guth, 1972; Koenderink, 1972). We now know that opponent processes occur early in the neural chain of events (DeValois, 1966), presumably already at the level of the retinal ganglion cells, going with nonlinear transformations of the receptor activities. The three-cone retinal phase alone accounts for the colour mixture laws, the further neural processing being unimportant for an understanding of these laws. But colour mixing laws describe only the beginning of the colour vision process. In fact the three-cone theory would never have been established without making additional assumptions on further processing beyond the receptor phase. Many of these assumptions seem to be confirmed by electrophysiology, especially those related to the intermediate levels in the colour vision process.

However, little or nothing is known about colour transducer functions, let alone about the metric structure of the colour signals at the more central level, where binocular mixing might take place. In an intriguing theoretical analysis, which leans heavily upon the experimental approach of Hurvich and Jameson (1957, 1972) Krantz (1972) proposed methods for establishing metric scales for redness, greenness, etc., which could probably be conceived of as transducer functions. However, apart from the virtual impossibility of constructing such scales independently, the theoretical results do not allow for an obvious extension towards dichoptic colour mixing.

What we want to know ultimately is what kind 
of colour signals are available at the level where binocular interaction may take place. All existing models end up with the splitting of signals into two chromatic channels and an achromatic channel. Gouras (1970) suggested a further combination of these kinds of signals. Stimulation of both eyes with different colours might be a tool to study the nature of the colour signals at a central level.

\section{SOME RELATED FINDINGS OF BINOCULAR INTERACTION IN GENERAL}

Helmholtz's notion of a completely independent development of the monocular percepts, without any organic link between the two visual pathways, has at least partly been ruled out by electrophysiological findings of binocular interactions in single cortical cells for cats and monkeys (Hubel and Wiesel, 1968; Pettigrew, Nikara and Bishop, 1968) and in single cells in other areas of the brain, such as the superior colliculi (Kadoya, 1971).

The existence of convergence of neural signals from both eyes, however, does not necessarily mean convergence of colour coded signals as well. The largely independent processing of different apsects of the visual stimuli does not allow for such a generalization. Some examples may clarify this statement.

(i) The colour adaptation effect for orthogonal gratings as described by McCollough (1965) does not show interocular transfer (Over, Long and Lovegrove, 1973), although this statement has been challenged by MacKay (1973). Frequency adaptation effects as found by Blakemore, Nachmias and Sutton (1970) do show an interocular transfer. Julesz (1971) interpreted these facts in the light of Hubel and Wiesel's finding of the exclusively monocular excitability of colour coded cells in the visual cortex.

(ii) Julesz's brightness contrast dot stereograms give rise to stable stereopsis, whereas stereograms, consisting of pure colour contrast dots fail to produce stereopsis (Lu and Fender, 1971). A very stable impression of depth can be obtained from disparate figures, differing in colour as long as brightness contrasts are not reversed, even in spite of very strong colour rivalry.

These considerations warn us that the rejection of Helmholtz's independency idea, does not necessarily point to a physiological central mixture process, and furthermore that we cannot directly derive the binocular colour combination process from knowledge about binocular brightness or contour combination processes. Our direct information on dichoptic colour combination processes is comparatively small.

The aim of this study is to provide basic data on dichoptic colour mixing, which are still missing in the literature, and without which further theorizing about this phase of the colour vision process seems to be impossible. These basic data concern the comparison of dichoptic mixing of stimuli of different wavelength with the monocular mixture of the same components. Before discussing the general experimental conditions we want to express some expectations about this way of comparison. Monocular colour mixing obeys Grassman's laws. Each colour can be matched by appropriate chosen amounts of three pri- maries. Changes of adaptation and multiplication of all components by a constant factor do not disturb the equivalence of the stimuli in the match, although colour appearance may change drastically. However, if we were able to match a dichoptic combination of two differently coloured stimuli by another dichoptic mixture or by a monoptic mixture of three primaries, this colour match is not likely to persist for an arbitrary change in adaptation conditions, nor for multiplication of all components by a same factor, or for adding a colour component. Another important, although strongly controversial law of monocular colour mixing. Abney's law, is certainly not obeyed in dichoptic colour mixing. As an example, Thomas, Dimmick and Luria (1961) found full summation of brightness for differently coloured lights in the two eyes, whereas averaging was the rule for equally coloured lights. Whether or not these findings can be upheld, important differences are to be expected in monocular and dichoptic mixtures of the same components. In view of these considerations, there is no direct reason to expect that the fusion product in a dichoptic combination of stimuli of different wavelength should give rise to an apparent colour which can be exactly matched with a monocular mixture of the same colour components in appropriate amounts. Earlier studies, however, showed this to be possible to a high degree. For instance, Thomas et al. (1961) used this procedure successfully. In other studies a related method was used. Livshitz (1940) compared a number of dichoptic red-green mixtures to a variable monocular mixture of 517 and $670 \mathrm{~nm}$. Trendelenburg (cited by Schrödinger, 1926) and Hoffman (1962) varied dichoptic red-green mixtures in order to match a standard monochromatic yellow. The possibility of such a two-component match obviously does not involve correctness of either Grassman's or Abney's laws for dichoptic mixtures. We decided to apply Thomas' type of comparison procedure, keeping in mind that it should be changed if strongly deviant results (impossibility of matchings) would be obtained.

\section{THE EXPERIMENTS}

In order to produce resonably stable dichoptic mixtures, certain general stimulation conditions should be used.

(i) According to Thomas et al. (1961) long exposure times are necessary to obtain stable colour fusion. This is the main conclusion too in nearly all older studies, except in Gunter's (1951) study (not mentioned in Das' review). In view of the exploratory character of our measurements we decided to work initially in the medium to long range of exposure durations, starting with $500 \mathrm{msec}$ as the lower limit.

(ii) Test stimuli presented on a dark background are better fused than stimuli on a light background according to Hering (1879) and Thomas (1961).

(iii) Although colour fusion is not completely excluded for dissimilarly contoured stimuli, complete spatial identity should be used, whereas stimuli should be small (Hering, 1879).

(iv) Because dichoptic-monoptic comparisons easily give rise to instabilities in the binocular system (Levelt, 1965), the "monoptic" mixtures must be 
presented binocularly. Thomas et al. also used this method. They presented test and comparison stimuli in adjacent fields. We use a separation between test fields and comparison fields, and between surround and test fields.

\section{Apparatus}

In Fig. 1 a diagram of the optical equipment is given. Monochromatic lights are provided by four Carl Zeiss prism monochromators, with tungsten filament lamps and/ or xenon arc lamps as lightsources. Test beams from $\mathrm{M}_{1 \text { t }}$ and $\mathrm{M}_{2 t}$ with wavelengths $\lambda_{i}$ and $\lambda_{j}$ resp., are reflected in beamsplitters $B_{1}$ and $B_{2}$ and subsequently pass through the lower parts of the test targets $\mathrm{T}_{1}$ and $\mathrm{T}_{2}$. Comparison lights of the same wavelengths, $\lambda_{i}$ and $\lambda_{j}$, from $\mathrm{M}_{1 c}$ and $\mathrm{M}_{2 c}$ resp., are combined into a common beam by beamsplitter prism $B_{3}$. The mixed-beam is split up again into two equivalent beams $\alpha$ and $\beta$ by an Al-film covered $90^{\circ}$ prism, $\mathrm{B}_{4}$. Beams $\alpha$ and $\beta$ pass over $\mathrm{B}_{1}$ and $\mathrm{B}_{2}$, before passing through the upper parts of the test targets. The exit slits of $\mathrm{M}_{1 v}, \mathrm{M}_{2 v}, \mathrm{M}_{1 c}$ and $\mathrm{M}_{2 c}$ are imaged upon the plane of the artificial pupils (AP), which have a circular diameter of $2 \mathrm{~mm}$. The targets are seen in Maxwellian view. The subject's head rests upon a chin rest and a forehead rest in order to fix the head more firmly. Pairs of mirrors $\mathrm{m}_{1}, \mathrm{~m}_{2}$ and $\mathrm{m}_{3}, \mathrm{~m}_{4}$ allow precise accommodation of the optical system to the subject's interpupillary distance and allow variation of the angle of convergence. Intensities of the lightsources are controlled by voltage regulation and by means of compensated circular neutral density wedges $\left(\mathrm{w}_{i}\right)$. We used a system of orthogonal polaroids $\mathrm{P}_{1}$ and $\mathrm{P}_{2}$ to control the relative amounts of the $\lambda_{i}$ and $\lambda_{j}$ components in the comparison mixture. An analyzer $\mathrm{P}_{3}$ could be rotated manually at a distance by the subject. If the inputs at $P_{3}$ from $M_{1 c}$ and $M_{2 c}$ are equal in luminance, then the output $\mathrm{P}_{3}$ is constant in luminance, independent of the angle of polarization if the polaroid's absorption characteristics do not differ for the two wavelengths. For the luminance calibrations subjects individually made flicker-photometric comparisons of both components, that is: left test colour, left comparison colours, right test colour and right comparison colours (as a control) against a con-
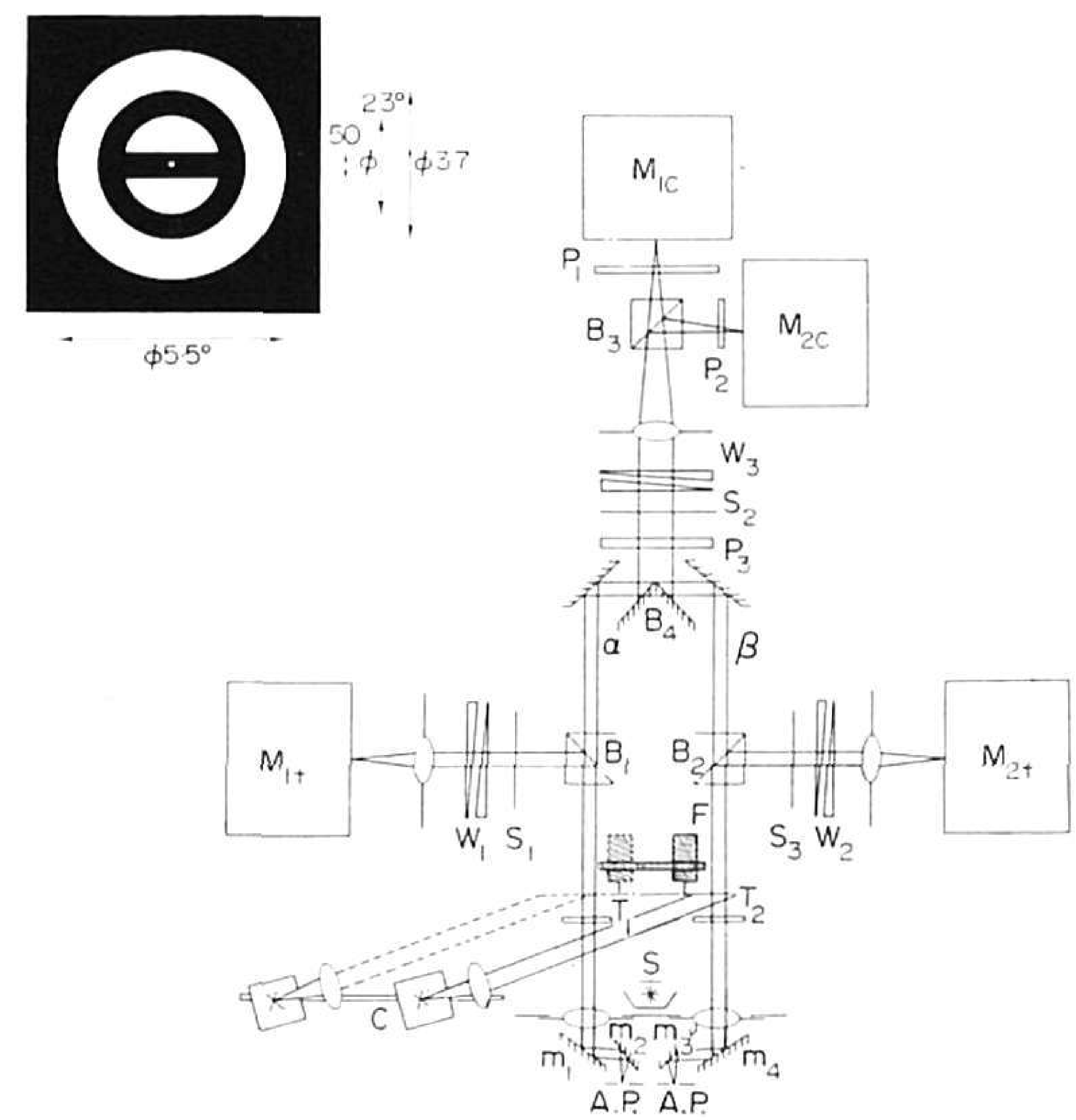

Fig. 1. Plan of the optical equipment: $\mathrm{M}_{i}$, monochromators; $\mathrm{B}_{i}$, beamsplitter prisms; $\mathrm{P}_{i}$, polaroid filters; $\mathrm{W}_{i}$, neutral density wedges; $S_{i}$, electromagnetic shutters; $F_{i}$, flicker vane; $\mathrm{T}_{i}$, test targets; $\mathrm{C}$, calibration light source; $\mathrm{S}$, surround illumination light source; A.P., artificial pupils; $\mathrm{m}_{i}$, system of mirrors forming the eye piece. stant calibration light patch, which was projected on a flicker vane just behind the target. The whole system of calibration light and flicker vane could simply be moved along an optical rail from left eye to right eye position. Equality in luminance at the observer's eye for the two orthogonally polarized comparison components does not necessarily mean equality in luminance at the position before the analyzer, because of different losses in the optical system for different angles of polarization. We return to this problem in the description of the procedure.

Targets. Targets were made of black araldite (door-plate material). The upper layer was removed by milling out a ring with o.d. of $6^{\circ}$ (in our optical equipment) and i.d. of $3.7^{\circ}$. A highly diffusing white surface is obtained in this way. A central hole, subtending $2.3^{\circ}$ was divided in two parts by a small $\left(50^{\prime}\right)$ horizontal stripe of matt black paper, upon which a small fixation point of white paper was attached in the middle. Surrounding ring and fixation point were illuminated from the frontside by a $50-\mathrm{W}$ halogen lamp, the intensity of which could be controlled.

Separation of surround from test and comparison fields and separation of test fields from comparison fields was necessary, in our view, to reduce unwanted binocular contour interactions at the one hand and to reduce simultaneous colour contrast effects at the other hand.

Modes of presentation. Three electromagnetic shutters $\left(\mathrm{S}_{1}, \mathrm{~S}_{2}, \mathrm{~S}_{3}\right)$ with 5 -cm circular openings, were controlled by means of a three-channel timer. The opening and closing times of the shutters were smaller than $10 \mathrm{msec}$. Presentation times of test and comparison could be set independently.

Subjects. Three male subjects (S, L and W) served in these experiments. All three had normal uncorrected vision and did not show any colour vision defect. One of the subjects (L) was known to be strongly right eye dominant.

Experiment 1. Colour mixing at low level of luminance and short presentation time

Stimuli. Test stimuli were chosen from a series of 13 possible wavelengths, ranging from 490 to $610 \mathrm{~nm}$ in 10$\mathrm{nm}$ steps. The retinal illumination level was set at $50 \mathrm{td}$. Illumination of the surrounding ring was $50 \mathrm{td}$ as well.

Procedure. Much care was taken to align the subject's centers of the pupils to the artificial pupils. Subjects were asked to fixate the central white spot between upper and lower fields. The subject subsequently equated the luminances of left test field of wavelength $\lambda_{i}$, the $\lambda_{i}$ component of the comparison mixture (at the $0^{\circ}$ position of $\mathrm{P}_{3}$ ) and the $i_{j}$ component of the comparison pair (at the $90^{\circ}$ position of $\mathrm{P}_{3}$ ). Then the whole calibration system was moved to the right eye position and the procedure was repeated for the $\lambda_{j}$ test stimulus in the right eye. Occasionally, as a control, both comparison components were checked for the right eye too.

After some minutes of adaptation to the surrounding ring luminance the test stimuli were presented for $500 \mathrm{msec}$ in the lower fields, followed after a $500-\mathrm{msec}$ pause by a 500-msec presentation of the comparison stimulus in the upper field. After a 500-msec pause, this cycle was repeated. The subjects were instructed to turn the analyzer knob such as to make an optimal colour match. In general, four to six repetitions were necessary to make a match. Each measurement was repeated at least five times. Next the $\lambda_{i}$ and $\lambda_{j}$ functions of the $\mathrm{M}_{1 c}$ and $\mathrm{M}_{2 c}$ were exchanged and matched in luminance again (flicker photometric matches can be carried out very quickly by experienced observers), after which the whole procedure was repeated. This interchange was necessary because of a possible asymmetry in the comparison beam.

All stimuli were combined with each other, except of course identical ones, and in most cases immediately neighbouring pairs, because of the nearly arbitrary adjustments of the analyzer in these matches. We measured the whole 
matrix of possible combinations in left and right eye, because of possible existence of eyc dominance effects

Comments made by the subjects concerning the quality and stability of the matches were noted by the experimenter.

Results. Judgments about the quality of the obtained matches differed slightly lor the different subjects. Most reports of instability were given by subject W. especially when a long wavelength stimulus was one of the mixture components. Subject $S$ reported rivalry in very few cases. In cases where the matches were not optimal. subjects were scarcely able to indicate the difference between monocular and dichoptic mixtures verbally. Generally, remarks concerned the desaturated character of the dichoptic mixture. This was not experienced however by subject S. Literature abounds in wather different descriptions of the modes of appearance of dichoptic colour combinations (Mecnes 1939: Johannsen. 1930: Thomas (t al.. 1961). A special form of colour dominance. the so called Köllner effect is sometimes observed. This effect has been brought back in the literature by Crovitz (1964). It is a special form of rivalry. in which the left visual field is dominated by the colour of the left eye stimulus, and the right visual field is dominated by the colour of the right eye stimulus. But the reverse maly occur as well (Crovitz. 1964).

All these modes of appearance have been reported now and then. but in general stable mixtures were obtained.

Sine square and cosine square of the angle of polarization of $P_{3}$ are used as indices for the relative amounts of the $\lambda_{i}$ and $\lambda_{j}$ components. that are necessary to match the dichoptic mixture of equiluminous amounts of $\lambda_{i}$ and $\lambda_{j}$ stimuli in left and right eve respectively.

In Table la for one subject the proportion of the ?. stimulus in the comparison mixture is given as a typical example. For convenience we only tabulated the $R\left(\lambda_{j}\right)$, values. which stand for the proportion of the $\lambda_{j}$ stimulus in the comparison mixture. when a $\lambda_{i}$ stimulus in the left eye is mixed with a $\lambda_{j}$ stimulus in the right eye. $L\left(\lambda_{i}\right)$, is the complement of $R\left(\lambda_{j}\right)_{\lambda_{1}}$. Figure 2 gives a graphical representation of these results. The results for the other two subjects are given later on in the section of the analysis. The strong decline of the contribution of the long wavelength stimuli is common to all observers.

\section{Preliminary discussion}

After completing experiment 1 we became rather concerned about various procedural aspects. Our first concern was the hardly photopic level of retinal illumination.

For one subject (W) a number of variations in the luminance level were tried out for a limited set of wavelength combinations. Retinal illumination was varied from 40 to about 1000 id for the 600-540 pair in left and right eye respectively. The method of the presentation was the same as that in experiment 1 . In Fig. 3a the results are given. There is a strong increase in the contribution of the $600-\mathrm{nm}$ stimulus necessary to obtain a match. This is especially so in the lower luminance part.

In another experiment right eye test stimuli of different wavelengths were combined with a 600-nm stimulus in the left eye. Matches were determined for two luminance levels, 30 and $300 \mathrm{td}$. As can be seen in Fig. 3b. an increase of the red contribution occurred for all mixtures. Although a strengthening of the long wavelength contribution occurs, the share

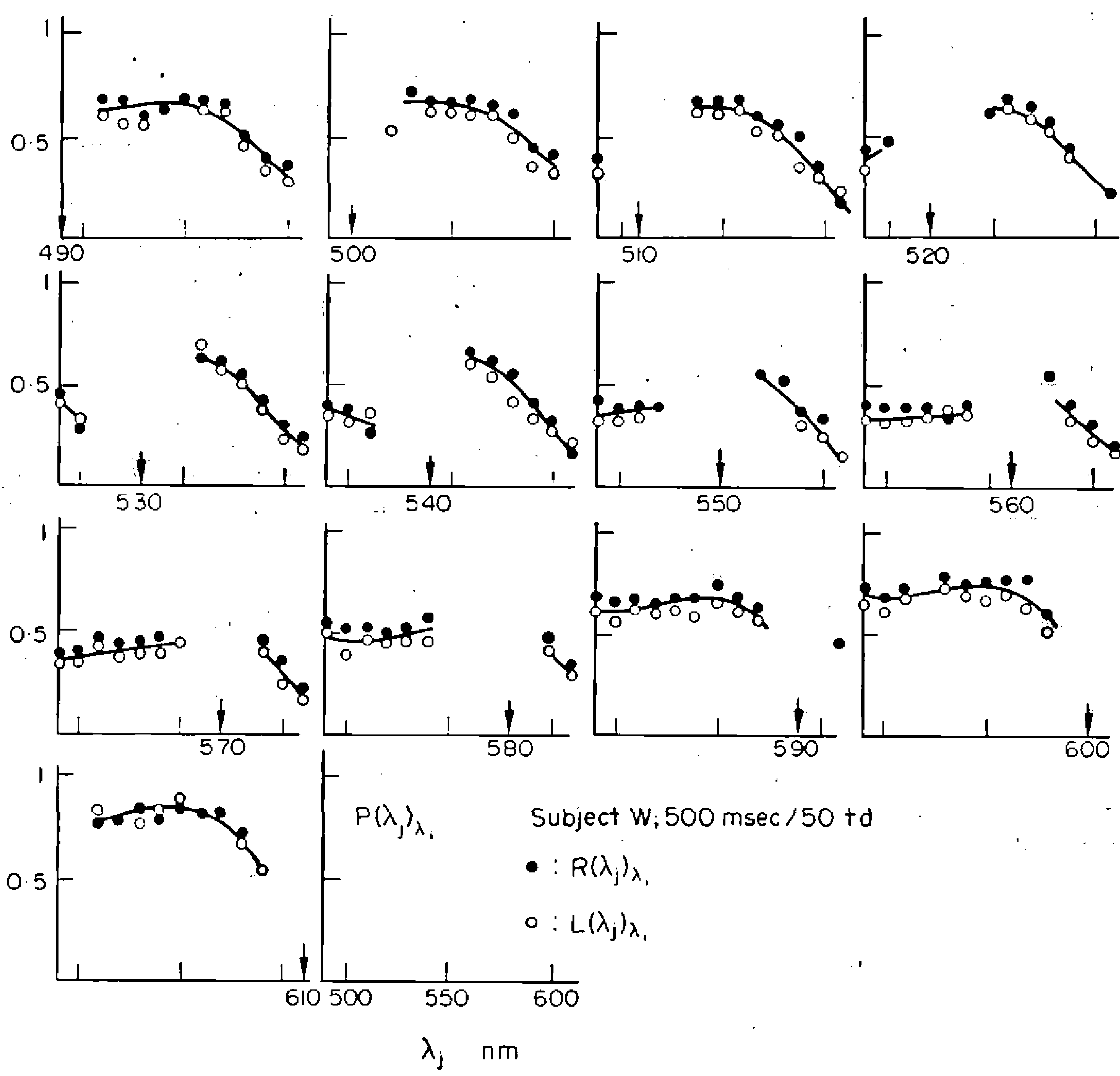

Fig. 2. Open symbols represent $L\left(i_{j}\right)_{\lambda_{1}}$ values, closed symbols represent $R\left(i_{j}\right)_{\lambda_{i}}$ values. $R\left(i_{j}\right)_{i_{i}}$ slands for the proportion of the $\lambda_{j}$ stimulus, necessary in the comparison stimulus to match a dichoptically presented mixture of a $i_{j}$ stimulus in the right eye and a $i_{i}$ stimulus in the left eye. $L\left(i_{j}\right)_{i_{1}}$ stands for the proportion of the $i_{i}$ stimulus in the comparison mixture. necessary to match a dichoptic mixture of a $i_{j}$ stimulus in the left eye and a $\lambda_{i}$ stimulus in the right eye. Arrows on the abscissa indicate the $i_{i j}$ stimuli. 


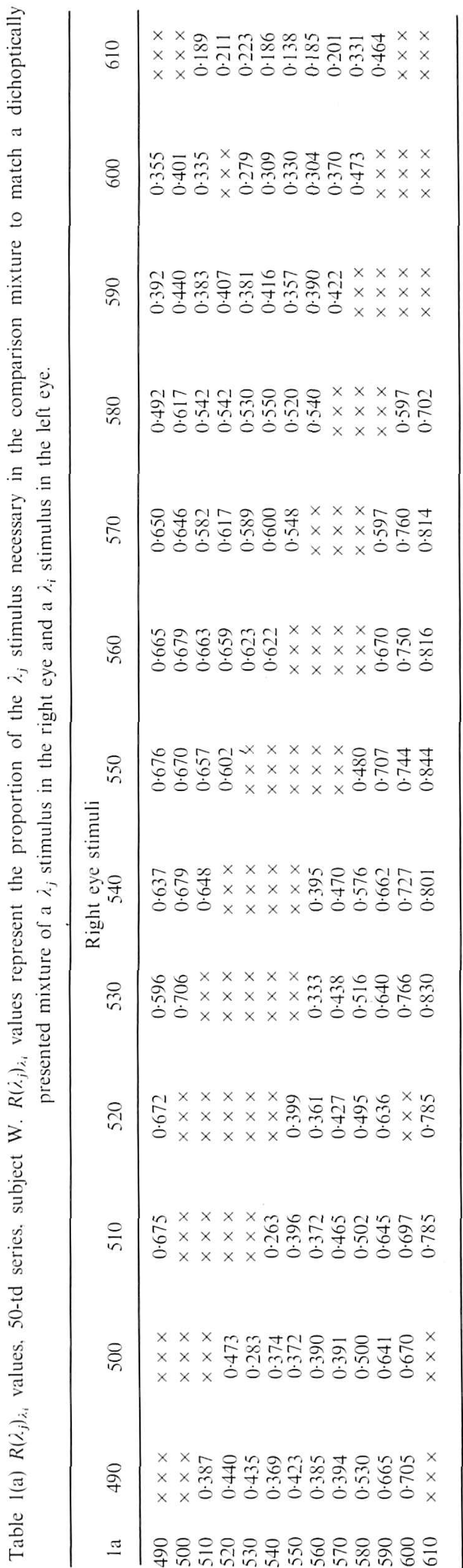

!nแu!ฺ วК ד

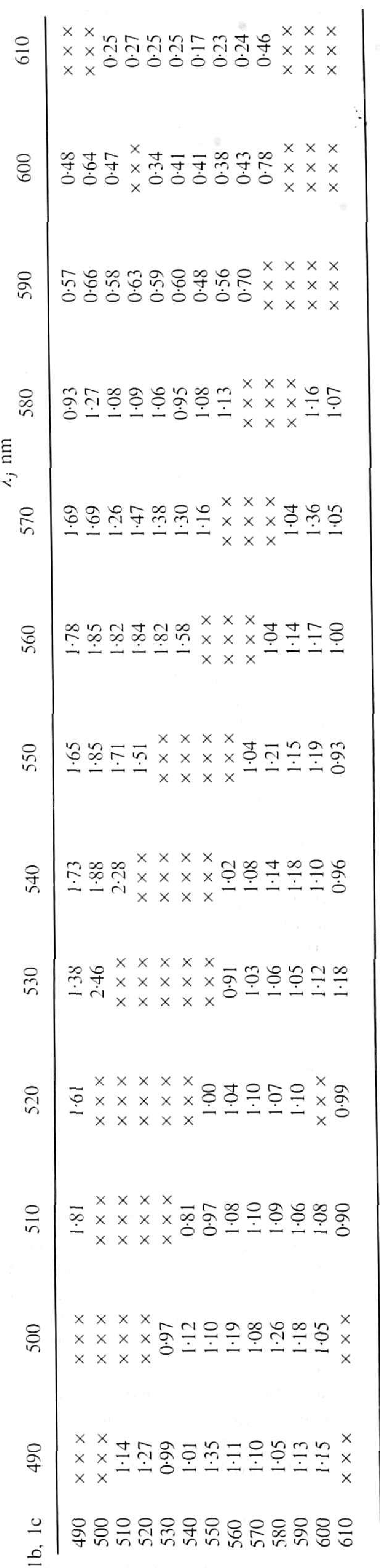

uu!' $\gamma$ 

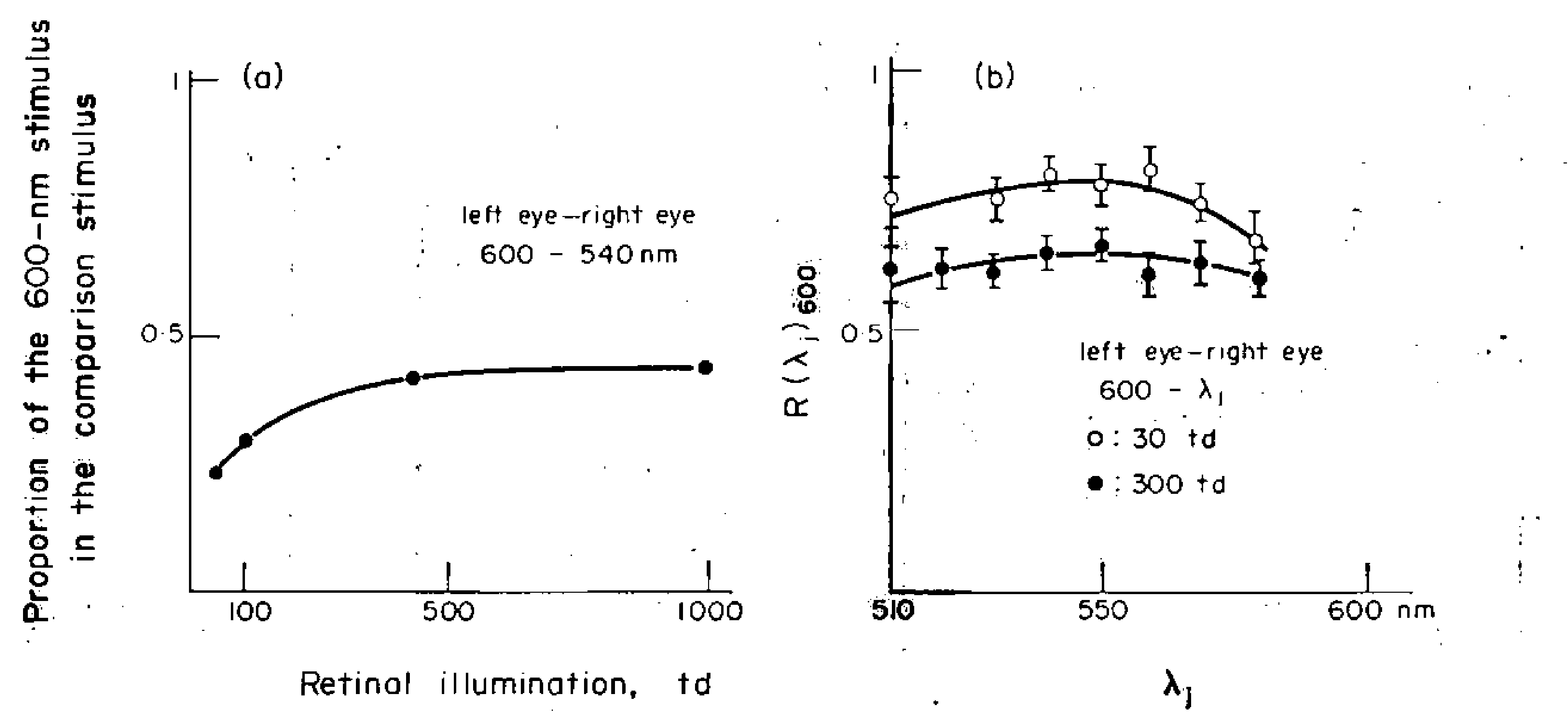

Fig. 3(a). Dependency of the $600-540-\mathrm{nm}$ mixture behaviour as a function of retinal illumination. (h) Behaviour of the $6(k)-i_{j}$ mixtures for two kevels of retinal illumination. For $R\left(\lambda_{i}\right)_{i_{1}}$, sec explanation in text.

of the red still remains below the level which could be expected if monocular and dichoptic mixing of colours would be the same, as has been reported by a number of authors. e.g. Livshitz (1940).

A second concern relates to the level of luminance of the comparison mixture. As was outlined in the description of the apparatus. calibration of the comparison lights at the $0^{\wedge}$ and $90^{\circ}$ positions of the analyzer, leads to a constant luminance of the comparison stimulus. independent of the colour. According to Thomas et al. (1961). however. stable dichoptic mittehes should only be obtained when the luminance of the comparison stimulus equalled twice the luminance of the test stimuli. We could simply realize this condition by equating the comparison components at the $45^{\circ}$ position of the polarizer $\mathrm{P}_{3}$. Whether or not the thesis of Thomas et al. would be upheld. we used this way of comparison because of the higher accuracy of the angle of polarization as an index for the proportions of the two comparison components in the mixture and also since all subjects in the first series reported the dichoptic mixture to be brighter than the comparison mixture in at least a number of cases.

Finally we found it useful to vary the mode of presentation in order to see whether our initial results would be strongly dependent upon the presentation condition. As an exploratory experiment we compared three modes of presentation for a 300-td level: (a) 500-msec presentation of test and comparison stimuli simultaneously, with a $500-\mathrm{msec}$ pause between the presentations; (b) 3-sec simultaneous presentation with a 500-msec paluse; (c) alternating 500msec presentation of test and comparison with a 500msec pause between them. Just as in experiment 1, about 4-6 repetitions were enough to make a match. Although there were very slight differences between the simultancous and the alternation method of presentation. we decided to use the 3 -sec simultancous presentation method for the second experimental series, because this mode of presentation gave rise to the most stable binocular mixtures.

Experiment 2. Colour mixing at a medium level of retinal illumination and long presentation time

Procedure. Test stimuli were equated in luminance at a 300-1d level. The comparison stimuli were equated at the 45 position of the analyzer. Test and comparison were presented simultancously in $3-\mathrm{sec}$ presentations, with off periods of $500 \mathrm{msec}$. The surrounding ring was kept at the same luminance as in the $500 \mathrm{mscc}$ series, that is at the 50-td level.

Results. The dichoptic mixtures turned out to be more stable than in the lower luminance series of experiment 1. In Table Za a typical example of the $R\left(i_{j}\right)$, matrix is given for onie subject. A global picture for all three subjects can be obtained from Fig. 4. The general pattern of results is similar to that of experiment 1. although some differences can be observed. The red decline is more pronounced in the low luminance series and furthermore the apparently enhanced predominance of the higher wavelength stimulus for neighbouring pairs seems to be more pronounced in the lower luminance series.

\section{Analysis of the results of experiment 1 and experiment 2}

Although our ultimate goal should be the resolution of the dichoptic colour mixing problem in terms of colour vision mechanisms. we first set ourselves the more limited aim of describing the results with a minimal number of variables. which may or may not be related to some colour vision mechanism. Because of the more stable character of the matches in the higher luminance series. we start the analysis with these data. The global picture presented in Fig. 4 suggests similar functions for all walvelengths. only differing in a shift along the ordinate. The $R\left(\hat{\lambda}_{j}\right)_{\lambda_{i}}$ curves suggest a simple two-factor description. One factor is related to a structural eye dominance, independent of wavelength, the other is related to a single wavelength dependent function.

Let $R\left(\lambda_{j}\right)$, and $L\left(\lambda_{i}\right)$, be the proportions of the amounts of $\lambda_{j}$ and $\lambda_{i}$ stimuli. necessally to match the dichoptic mixture of equally luminous amounts of $\lambda_{i}$ and $\lambda_{j}$ in left and right eye respectively. We propose that

$$
\frac{R\left(\lambda_{\cdot j}\right)_{\lambda_{i}}}{U\left(\lambda_{i}\right)_{\lambda_{j}}}=c\left(\lambda_{i_{j}} \lambda_{i j}\right) \cdot d_{r}
$$

in which $d_{r}$ represents a structural eye dominance factor and $c\left(\lambda_{j} \lambda_{i}\right)$ represents a simple function:

$$
c\left(\lambda_{j} \lambda_{i}\right)=\frac{c^{\prime}\left(\lambda_{j}\right)}{c^{\prime}\left(\lambda_{i}\right)}
$$


and

$$
c\left(\lambda_{i} \lambda_{j}\right)=\frac{c^{\prime}\left(\lambda_{i}\right)}{c^{\prime}\left(\lambda_{j}\right)}
$$

$d_{r}$ and $c\left(\lambda_{j} \lambda_{i}\right)$ values can be computed from:

$$
\frac{R\left(\lambda_{j}\right)_{\lambda_{i}}}{L\left(\lambda_{i}\right)_{\lambda_{j}}} \cdot \frac{R\left(\lambda_{i}\right)_{\lambda_{j}}}{L\left(\lambda_{j}\right)_{\lambda_{i}}}=d_{r}^{2}
$$

and

$$
\frac{R\left(\lambda_{j}\right)_{\lambda_{i}}}{L\left(\lambda_{i}\right)_{\lambda_{j}}} \cdot \frac{L\left(\lambda_{j}\right)_{\lambda_{i}}}{R\left(\lambda_{i}\right)_{\lambda_{j}}}=\left(c\left(\lambda_{j} \lambda_{i}\right)\right)^{2}
$$

These values were computed for all three subjects. In order to save space we only present the complete tables for subject W: Tables $1 \mathrm{~b}$ and $\mathrm{c}$ for the first experimental series, Tables $2 \mathrm{~b}$ and $\mathrm{c}$ for the second experiment.

For an evaluation of this simple description we have to consider: (1) the variation in $d_{r}$; and (2) the amount of fit obtained when the mean value of $d_{r}$ and the best fitting $c^{\prime}(\lambda)$ function are used to reconstruct the $R\left(\lambda_{j}\right)_{\lambda_{i}}$ values for all the experimentally determined combinations.

The $d_{r}$ values for subjects $\mathrm{S}$ and $\mathrm{W}$ seem to be reasonably constant as can be seen in the inscribed table in Fig. 5. For subject $\mathrm{L}$ the variation in $d_{r}$ is larger, especially in the 50-td series.

It still seems sensible, to see how much of the variance can be explained by the two factor description. In order to obtain such a measure, we determined the best fitting $c^{\prime}(\lambda)$ function with the aid of Gulliksen's least squares procedure for incomplete matrices (Torgerson, 1958) in the following way:

$$
\begin{aligned}
\text { Let } Q(i, j) & =\frac{R\left(\lambda_{i}\right)_{\lambda_{j}}}{1-R\left(\lambda_{i}\right)_{\lambda_{j}}}=\frac{c^{\prime}\left(\lambda_{i}\right)}{c^{\prime}\left(\lambda_{j}\right)} \cdot d_{r}, \\
Q(j, i) & =\frac{R\left(\lambda_{j}\right) \lambda_{\lambda_{i}}}{1-R\left(\lambda_{j}\right)_{\lambda_{i}}}=\frac{c^{\prime}\left(\lambda_{i}\right)}{c^{\prime}\left(\lambda_{j}\right)} \cdot d_{r}
\end{aligned}
$$

and

$$
\frac{Q(i, j)}{Q(j, i)}=w(i, j)=\left[\frac{c^{\prime}\left(\lambda_{i}\right)}{c^{\prime}\left(\lambda_{j}\right)}\right]^{2} .
$$

Taking $\frac{1}{2} \log w(i, j)=\Phi(i, j)$, we get $\Phi(i, j)=\log c^{\prime}\left(\lambda_{i}\right)$ - $\log c^{\prime}\left(\lambda_{j}\right)$. In Gulliksen's least square program $L=\Sigma_{i j}\left[\Phi(i, j)-\log c^{\prime}(\lambda)-\log c^{\prime}(\lambda)\right]^{2}$ is minimized, with $c^{\prime}(\lambda)$ as the variable. The amount of fit is expressed in the form of a loss function of the form

$$
P=\sqrt{\sum_{i j} \frac{\left[\hat{R}\left(\lambda_{j}\right)_{\lambda_{i}}-R\left(\lambda_{j}\right)_{\lambda_{i}}\right]^{2}}{\sum_{i j} R\left(\lambda_{j}\right)_{\lambda_{i}}^{2}}}
$$

in which $\hat{R}\left(\lambda_{j}\right)_{\lambda_{i}}$ is the reconstructed $R\left(\lambda_{j}\right)_{i_{i}}$ value. $P$ is related to the amount of variance, explained by the 2 -factor description as $(1-P) .100 \%$.

In Fig. 5, the best fitting $c^{\prime}(\lambda)$ functions are shown for the three subjects in the two experiments. In the inscribed table the stress values $(P)$ are also indicated. In Figs. 6-8, the reconstructed $R\left(\lambda_{j}\right)_{\lambda_{i}}$ values are represented together with the empirical $R\left(\lambda_{j}\right)_{\lambda_{i}}$ values. For two subjects, L and W, the inaccuracy of the experimentally determined $R$ values is indicated for a number of measurements. Generally a S.D. of about

\begin{tabular}{|c|c|c|c|c|c|c|c|c|}
\hline & \multicolumn{8}{|c|}{ Right eye stimuli } \\
\hline & $5 a$ & 510 & 530 & 550 & 570 & 590 & 610 & 630 \\
\hline \multirow{7}{*}{ 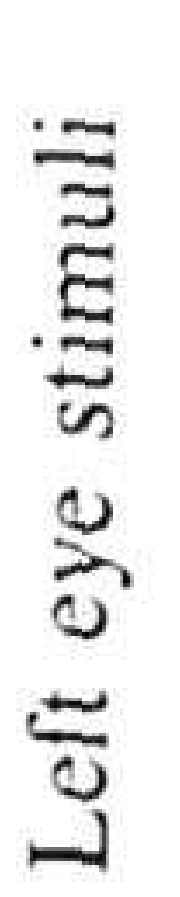 } & 510 & $\times \times \times$ & $x \times \times$ & $0 \cdot 520$ & $0 \cdot 535$ & $0 \cdot 500$ & $0 \cdot 337$ & $0 \cdot 190$ \\
\hline & 530 & $\times \times \times$ & $\times \times \times$ & $x \times x$ & 0.535 & $0 \cdot 475$ & $0 \cdot 290$ & $0 \cdot 207$ \\
\hline & 550 & $0 \cdot 450$ & $x \times x$ & $x \times x$ & $0 \cdot 500$ & $0 \cdot 450$ & $0 \cdot 306$ & $0 \cdot 165$ \\
\hline & 570 & $0 \cdot 425$ & 0.460 & 0.475 & $x \times x$ & $0 \cdot 450$ & $0 \cdot 263$ & $0 \cdot 225$ \\
\hline & 590 & $0 \cdot 497$ & $0 \cdot 530$ & $0 \cdot 580$ & $x \times x$ & $\times \times \times$ & $0 \cdot 430$ & $0 \cdot 263$ \\
\hline & 610 & 0.673 & $0 \cdot 723$ & $0 \cdot 725$ & 0.737 & 0.595 & $x \times x$ & $x \times x$ \\
\hline & 630 & $0 \cdot 801$ & $0 \cdot 817$ & $0 \cdot 815$ & $x \times x$ & $0 \cdot 690$ & $x \times x$ & $x \times x$ \\
\hline
\end{tabular}
$10 \%$ is found. One might ask to what extent the inaccuracy of the measurements corresponds to reports of rivalry. We did not find an obvious correlation.

\begin{tabular}{|c|c|c|c|c|c|c|c|c|}
\hline & $5 b, 5 c$ & 510 & 530 & 550 & $\begin{array}{c}\lambda_{j} \\
570\end{array}$ & $\begin{array}{l}\mathrm{nm} \\
590\end{array}$ & 610 & 630 \\
\hline \multirow{7}{*}{$\begin{array}{l}\underset{\Xi}{\Xi} \\
\therefore\end{array}$} & 510 & $\times \times \times$ & $\times \times \times$ & $1 \cdot 15$ & $1 \cdot 25$ & $1 \cdot 00$ & 0.47 & $0 \cdot 24$ \\
\hline & 530 & $\times \times \times$ & $\times \times \times$ & $\times \times \times$ & $1 \cdot 16$ & $0 \cdot 90$ & $0 \cdot 39$ & $0 \cdot 24$ \\
\hline & 550 & 0.945 & $\times \times \times$ & $\times \times \times$ & 1.05 & 0.77 & $0 \cdot 41$ & $0 \cdot 21$ \\
\hline & 570 & 0.970 & 0.990 & 0.950 & $\times \times \times$ & 0.94 & $0 \cdot 36$ & $0 \cdot 26$ \\
\hline & 590 & 0.995 & $1 \cdot 01$ & $1 \cdot 06$ & 0.99 & $\times \times x$ & 0.72 & $0 \cdot 36$ \\
\hline & 610 & 1.02 & $1 \cdot 02$ & $1 \cdot 08$ & $1 \cdot 00$ & 1.05 & $\times \times \times$ & $\times \times \times$ \\
\hline & 630 & 0.975 & 1.08 & 0.935 & $\times \times \times$ & 0.89 & $\times \times x$ & $\times \times \times$ \\
\hline
\end{tabular}
It seems that, if any criterion has been taken, subjects are reasonably able to maintain it.

Table 2(a) $R\left(\lambda_{j}\right)_{\lambda,}$ values. 300-td series, subject W. (See legend of Table 1a)

(b) (lower triangle): $d_{r}$ values. (c) (upper triangle): $c\left(\lambda_{j} \lambda_{i}\right)$ values. (See legend of Tables $1 \mathrm{~b}$ and $\mathrm{c}$ ) 

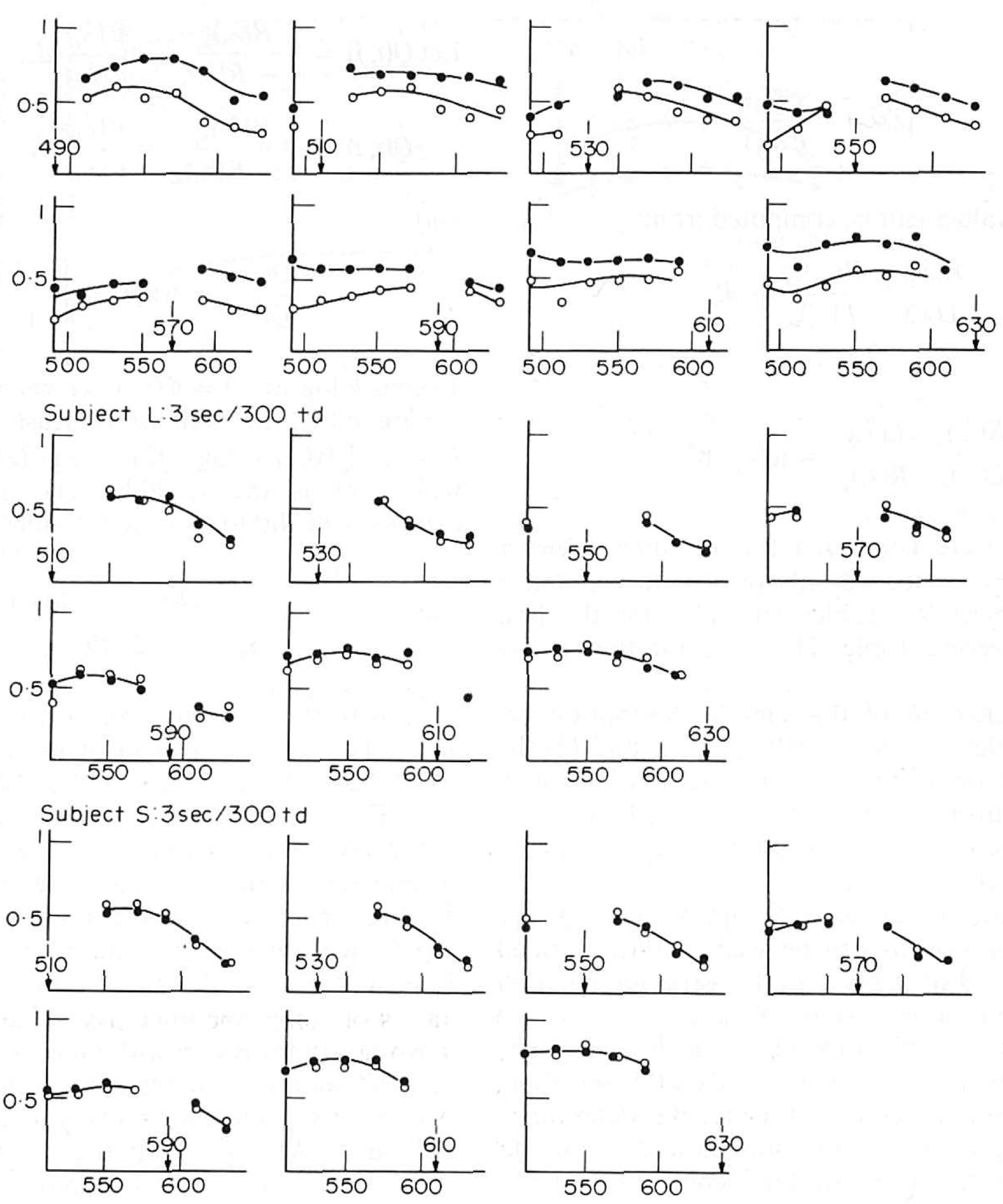

Subject $W: 3 \mathrm{sec} / 300+d$

Fig. 4. See legend of Fig. 2.

For subject L, systematic deviations of $d_{r}$ occur, especially in the 490-nm series. The 2-factor description seems to be not fully adequate for his case, although it explains about $90 \%$ of the experimental variance. Moreover, the general characteristics are the same as for the other subjects, as can be seen in Fig. 5. Common to all observers is the change in $c^{\prime}(\lambda)$ at the high wavelength side for the two levels of luminance. This corresponds to the earlier findings for a limited set of stimuli for subject W (Fig. 3).

The course of the $c^{\prime}(\lambda)$ function can simply be expressed in terms of chromaticity coordinates. If a stimulus of luminance $L_{1}$ and chromaticity $x_{1}, y_{1}$ is mixed monoptically with another stimulus of luminance $L_{2}$ and chromaticity $x_{2}, y_{2}$, then the mixture product has chromaticity coordinates given by:

$x_{m}=\frac{x_{1} y_{2} L_{1}+x_{2} y_{1} L_{2}}{y_{2} L_{1}+y_{1} L_{2}}$ and $y_{m}=\frac{y_{1} y_{2}\left(L_{1}+L_{2}\right)}{y_{2} L_{1}+y_{1} L_{2}}$.

For $L_{1}=p \cdot L_{2}$, these expressions are reduced to

$$
x_{m}=\frac{p x_{1} y_{2}+y_{1} x_{2}}{p y_{2}+y_{1}} \text { and } y_{m}=\frac{(1+p) y_{1} y_{2}}{p y_{2}+y_{1}} .
$$

As we measured the dichoptic mixtures in terms of monoptic mixtures of the same components, we can interpret the $c^{\prime}(\lambda)$ function as a kind of relative efficiency function, specific for the dichoptic combination. This, because of the fact that the dichoptic mixture of equiluminous test stimuli of wavelengths $\lambda_{1}$ and $\lambda_{2}$ matches a monoptic mixture of the same components, which are now unequal in luminance. It is as if $L_{1}\left(\lambda_{1}\right)$ is effectively reduced or heightened with respect to $L_{2}\left(\lambda_{2}\right)$ according to:

$$
L\left(\lambda_{1}\right)=\frac{c^{\prime}\left(\lambda_{1}\right)}{c^{\prime}\left(\lambda_{2}\right)} \cdot L\left(\lambda_{2}\right)
$$

\section{DISCUSSION}

A number of earlier findings in dichoptic colour mixing experiments can roughly be fitted into the $c^{\prime}(\lambda)$ picture. Rochat (1922) found a strong dominance of the green stimulus in an attempt to determine the Rayleigh equation for a dichoptic mixture of red (671 $\mathrm{nm})$ and green $(535 \mathrm{~nm})$ into yellow $(589 \mathrm{~nm})$. Trendelenburg (cited in Schrödinger, 1926), and Hoffman 

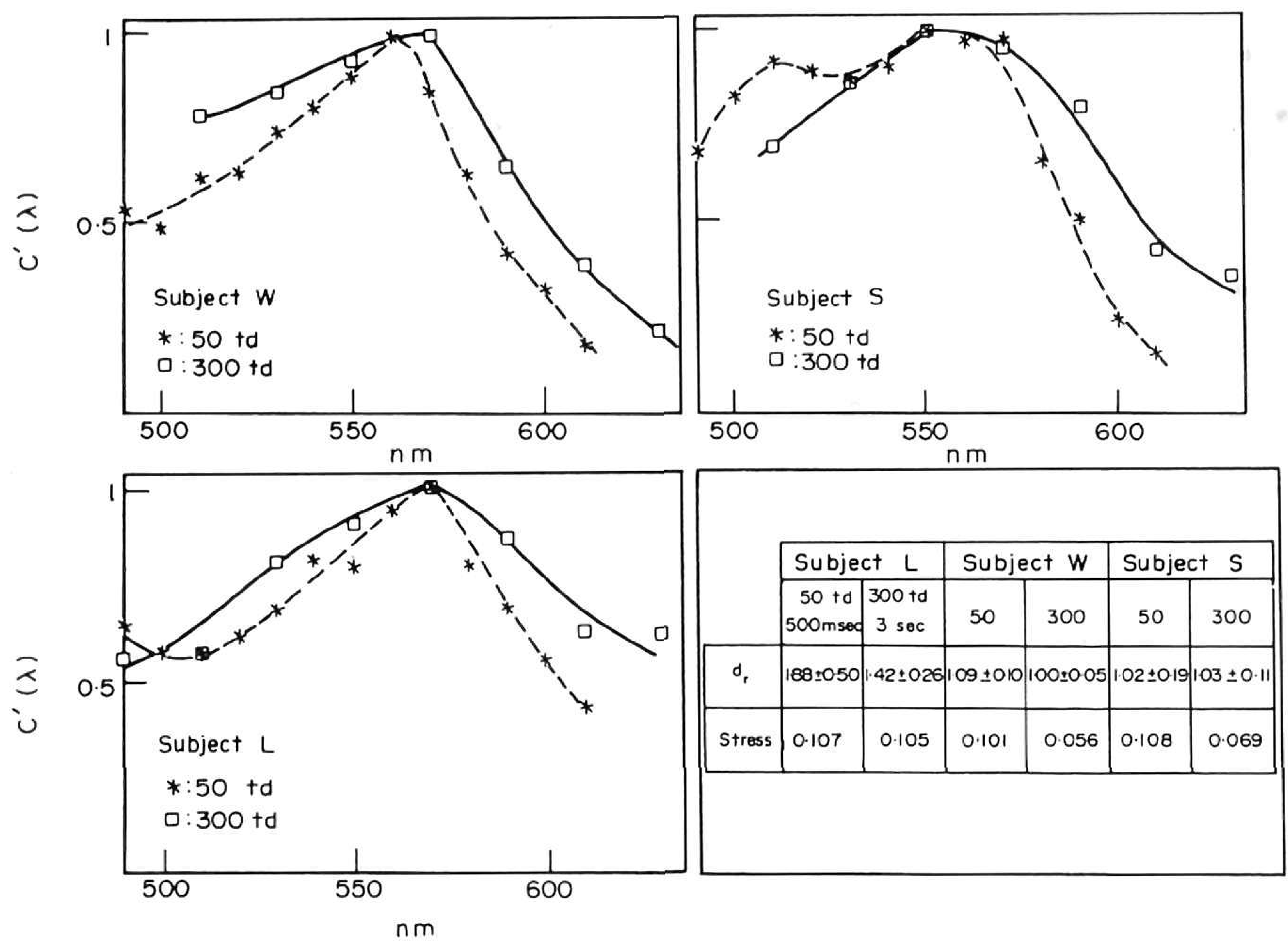

Fig. 5. Best fitting $c^{\prime}(\lambda)$ functions. The inscribed table represents $d_{r}$ and $P$ values.

(1962) compared the relative amounts of red and green stimuli, necessary to match a monochromatic yellow standard in a monoptic and in a dichoptic mixture. The ratio of the amounts of 535 and 671 nm stimuli, necessary for the match of a $589-\mathrm{nm}$ standard, was about 8 times larger for the monoptic match than it was for the dichoptic match in Trendelenburg's study, whereas in Hoffman's study the dif-

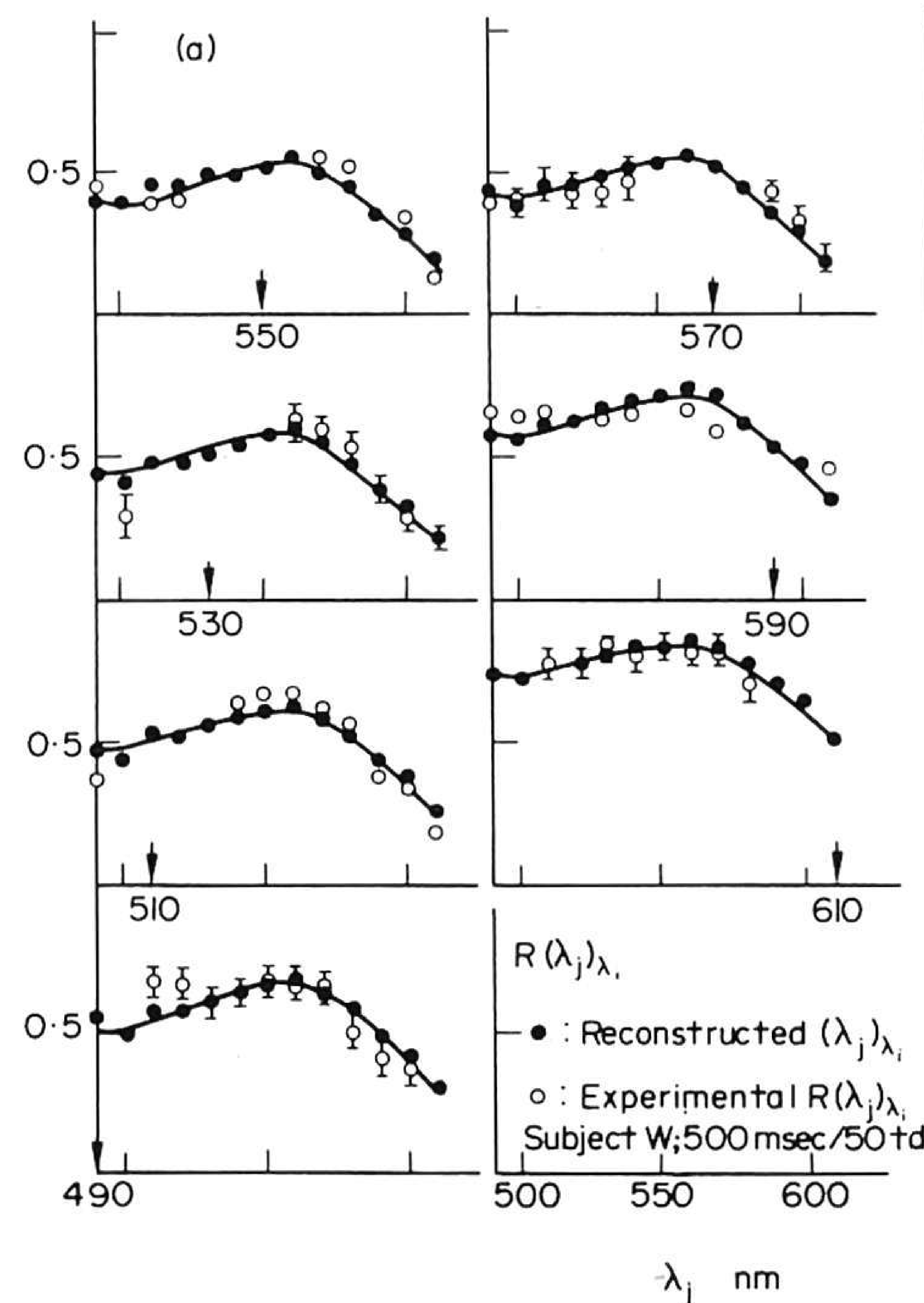

ference factor was about 1.50 for the 533-631-nm match of a $582-\mathrm{nm}$ standard. The $c^{\prime}(\lambda)$ picture also appears in a series of experiments on the mixture ratios of complementary colours, necessary to match a white comparison both monoptically and dichoptically (Trendelenburg, as cited by Schrödinger, 1926). In a fruitless attempt to evoke a sensation of yellow in a dichoptic combination of unique red and unique

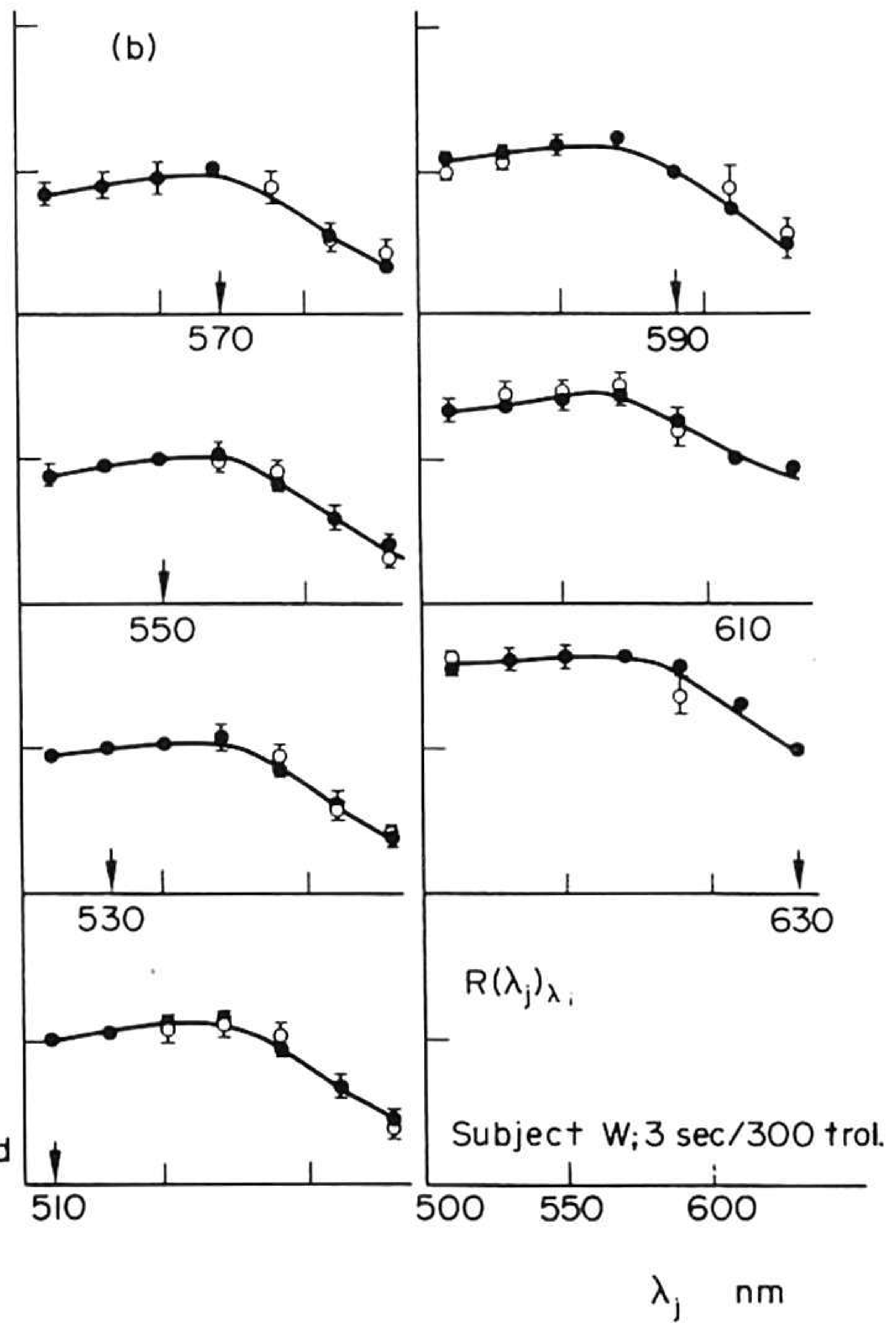

Fig. 6. (a) Open symbols represent the experimentally obtained $R\left(\lambda_{j}\right)_{\lambda_{i}}$ values, closed symbols stand for the reconstructed $R\left(\lambda_{j}\right)_{\lambda_{1}}$ values for the 50-td series. Subject W. (b) Open symbols represent the experimentally obtained $R\left(\lambda_{j}\right)_{\lambda_{i}}$ values, closed symbols stand for the reconstructed $R\left(\lambda_{\lambda_{j}}\right)_{\lambda_{i}}$ values for the 300-td series. Subject W. 

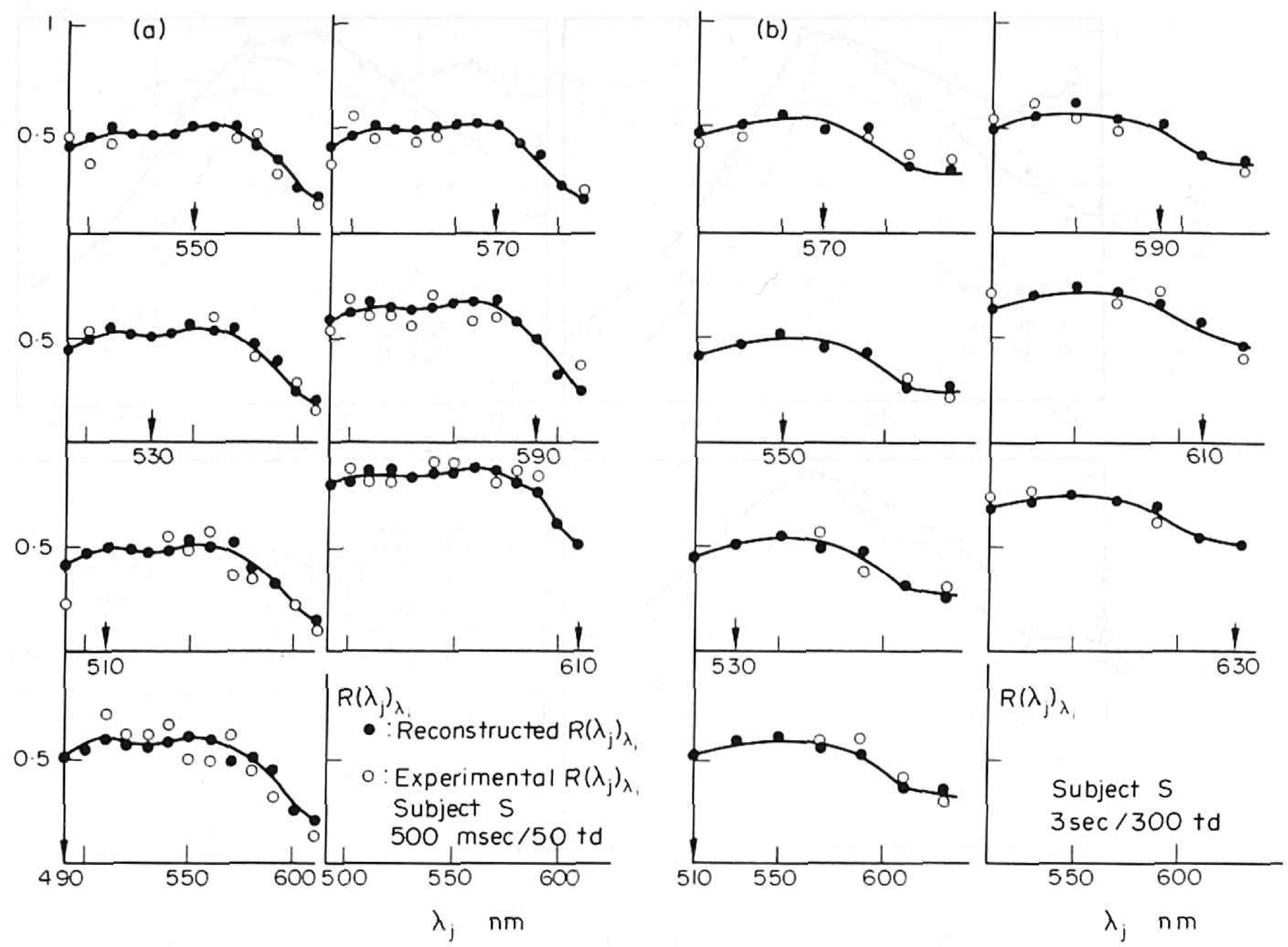

Fig. 7. See legend of Fig. 6. Subject S.

green stimuli, Hurvich and Jameson (1951) obtained a colourless impression, but they needed a ratio of red to green which was much larger than the ratio necessary to get a hueless impression in a monoptic mixture of the same components. The predominance of the middle wavelength stimuli over red and blue stimuli was also reported by Thomas et al. (1961), at least for part of their experiments.

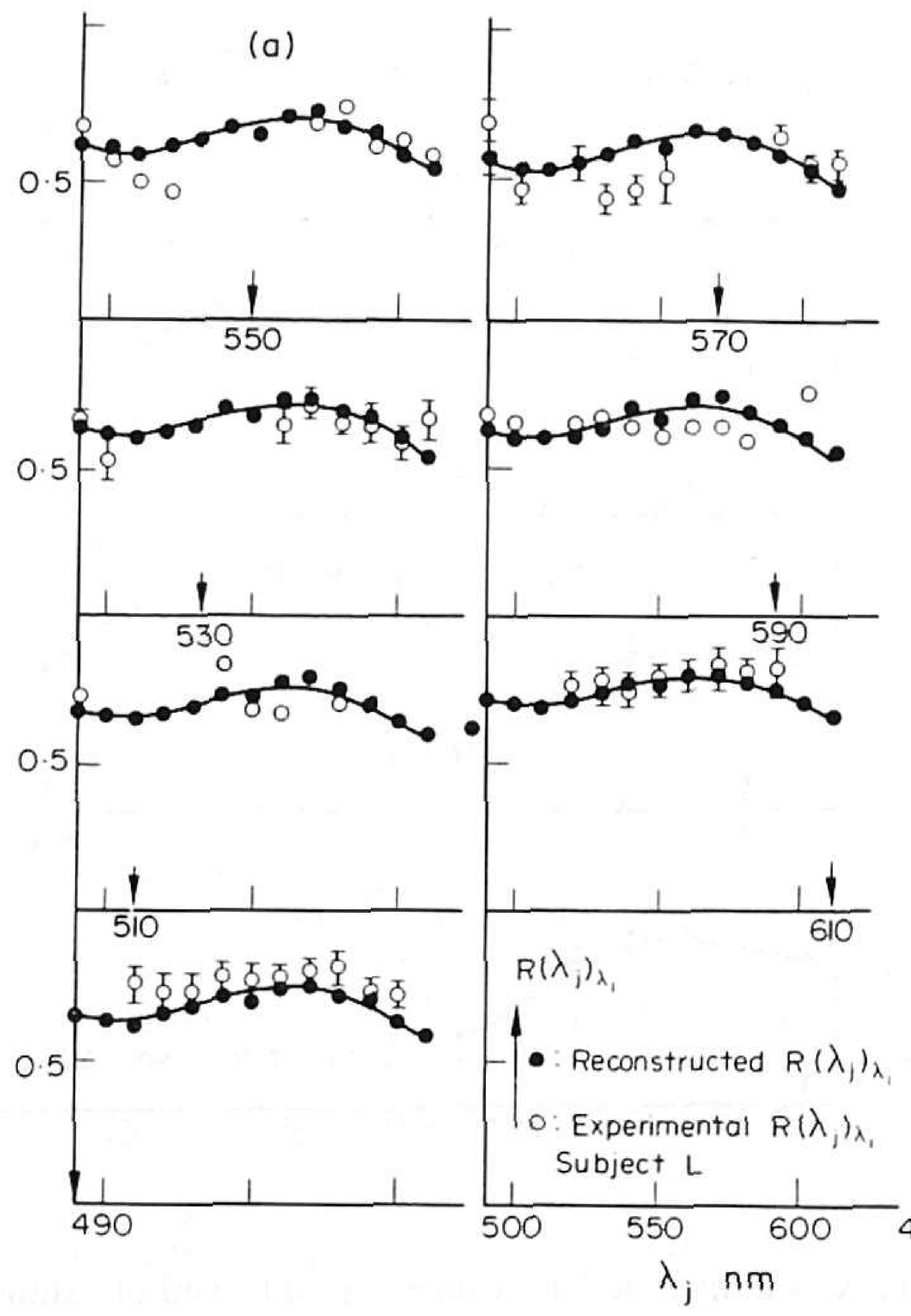

(a) : $500 \mathrm{msec} / 50+d$
We will now turn to some general concluding remarks:

(i) The most general conclusion is that a large part of the variance in our dichoptic colour mixing results can be explained by a 2-factor model, with one component a wavelength dependent dichoptic efficiency function, $c^{\prime}(\lambda)$, and the other component a general eye dominance factor.

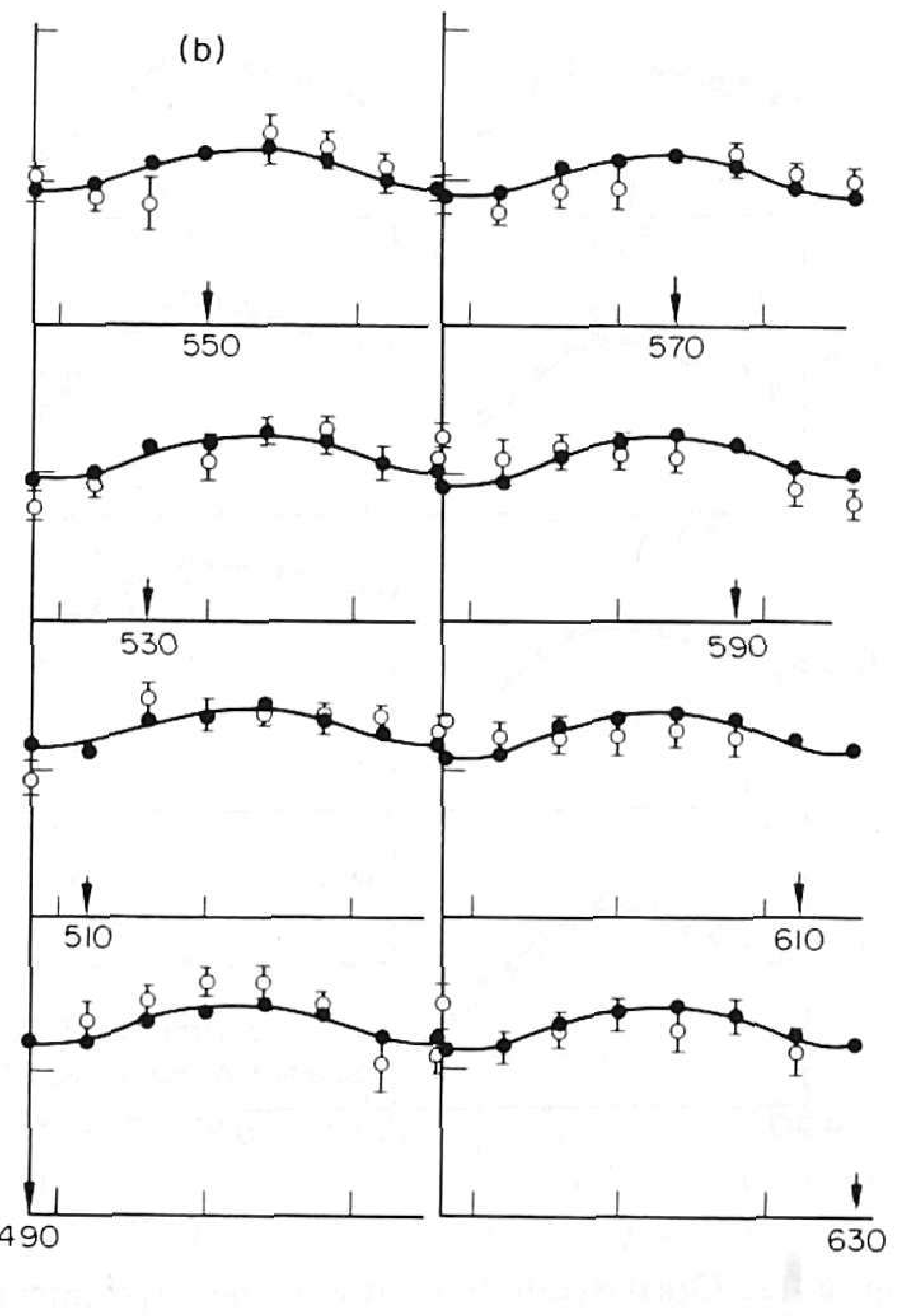

(b): $3 \mathrm{sec} / 300+d$

Fig. 8. See legend of Fig. 6. Subject L. 
(ii) These results were obtained under the assumption that a dichoptic mixture can be matched in colour by appropriate chosen amounts of the same components in a monoptic comparison mixture. For the region of wavelengths under concern, this assumption could be maintained to a high degree, but we must remark that complete indistinguishability of the two types of colour mixtures is seldom attained. Often a difference in saturation is noticed, and in a number of cases especially when green-red mixtures were presented, other kinds of differences were noticed, which can hardly be expressed verbally.

(iii) The $c^{\prime}(\lambda)$ results should be interpreted very carefully, since the mixture results may be dependent upon the type of surround illumination used. Experiments in which this variable is further studied are to be reported in another paper.

(iv) Though under the present conditions we have generally been able to obtain stable mixtures, there are many conditions under which such stable mixtures do not occur. Much information about the combination process can probably be obtained from the unstable phases of the binocular colour combination process. Only very few data are available on this point. Pickford's (1947) index of fuseability, derived in a factor analysis of stability judgments shows a resemblance to our $c^{\prime}(\lambda)$ function. The precise relation between these quantities, however, is still unclear.

(v) As to the interpretation of the data, the 2-factor description represents only a first step towards the explanation of the mixture phenomena. Further steps should entail a proposal as to the central integration of peripherally arising opponent colour codes. The challenge of dichoptic experiments is especially to consider the central integrative phase of colour perception, which is usually left out of consideration in monoptic colour work.

In a later paper we will try to present further steps towards such a model. Suffice it to say here that we see no reason to explain phenomena, such as dichoptic yellow from monocular red and green stimuli, in terms of the radical approach of Hecht (1928), who considered yellow synthesis as a central process for both the monoptic and the dichoptic case. In our view the existence of dichoptic yellow can very well be integrated with the presently doubtless facts about the early locus (before binocular convergence) of yellow coding. Both the red and the green stimuli evoke a certain activity in the yellow-blue channels for the two eyes, and we think it is this common activity which forms the stable basis for dichoptic colour mixtures. Apart from the common yellow activity, a further contribution to the stability of the dichoptic colour mixture must be ascribed to the amount of achromatic activity common in the two channels.

It remains to be seen whether colour codes enter directly into a binocular combination process, or that the different colour codes are first combined into higher order codes, before binocular combination occurs. It also remains to be seen whether opponent qualities are cancelled (Hurvich and Jameson, 1951), in a way analogous to the cancellation process in the peripheral colour coding, or that one or the other member of the opponent components attains complete dominance in the dichoptic case.

\section{REFERENCES}

Blakemore C., Nachmias J. and Sutton P. (1970) The perceived spatial frequency shift: evidence for frequency selective neurones in the human brain. J. Physiol., Lond. 210, 727-750.

Bouman M. A. (1969) My image of the retina. Q. Rev. Biophys. 2, 25-64.

Crovitz H. F. (1964) Retinal locus in tachistoscopic binocular color rivalry. Percept. Mot. Skills 19, 808-810.

Das S. R. (1953) Binocular color mixture. Thesis, University of Illinois.

DeValois R. L., Abramov I. and Jacobs G. H. (1966) Analysis of response patterns of LGN cells. J. opt. Soc. Am. 56, 966-977.

Dunlap K. (1944) Alleged binocular color mixing. Am. J. Psychol. 57, 559-563.

Gouras P. (1970) Trichromatic mechanisms in single cortical neurons. Science 168, 489-492.

Gunter R. (1951) Binocular fusion of colours. Br. J. Psychol. 17, 363-372.

Guth S. L. (1972) A new color model. In Color Metrics (Edited by Vos J. J., Friele L. F. C. and Walraven P. L.). AIC, Soesterberg. The Netherlands.

Hassenstein B. (1968) Modellrechnung zur Datenverarbeitung beim Farbensehen des Menschen. Kybernetik 4, 209-233.

Hecht S. (1928) On the binocular fusion of colors and its relation to the theories of color vision. Proc. natn. Acad. Sci. U.S.A. 14, 237-241.

Hering E. (1879) In Handbuch der Physiologie der Sinnesorgane (Edited by Hering E., Fick A. and Kühne W.). Vogel, Leipzig.

Hoffman C. S. (1962) Comparison of monocular and binocular color matching, J. opt. Soc. Am. 52, 75-80.

Hubel D. H. and Wiesel T. N. (1968) Receptive fields and functional architecture of monkey striate cortex. J. Physiol., Lond. 195. 215-243.

Hurvich L. M. and Jameson D. (1957) An opponent-process theory of color vision. Psychol. Rev. 64, 384-404.

Hurvich L. M. and Jameson D. (1951) The binocular fusion of yellow in relation to color theories. Science 114, 199202.

Jameson D. (1972) Theoretical issues of color vision. In Handbook of Sensory Psychology, Vol. 7/4, Chap. 14. Springer, Berlin.

Johannsen D. E. (1970) A quantitative study of binocular color vision. J. gen. Psychol. 4, 282-308.

Julesz B. (1971) Foundations of Cyclopean Perception. University of Chicago Press.

Kadoya S., Wolin L. R. and Massopust L. C. (1971) Photically evoked unit activity in the tectum opticum of the squirrel monkey. J. comp. Neurol. 142, 495-508.

Koenderink J. J. (1972) Opponent color coding. A Mechanistic model and a new metric for color space. Thesis, Utrecht.

Krantz D. H. (1971) Color measurement and color theory. Michigan Mathematical Psychology Program, Rep MMPP 71-3 and MMPP 71-4.

Krantz D. H. (1972) Measurement theory and qualitative laws in psychophysics, Michigan Mathematical Psychology Program, Rep MMPP 72^3.

MacKay M. and MacKay V. (1973) Orientation sensitive aftereffects of dichoptically presented colour and form. Nature, Lond. 242, 477-479.

McCollough C. (1965) Color adaptation of edge detectors in the human visual system. Science 149, 1115-1116.

Meenes M. (1930) A phenomenological description of retinal rivalry. Am. J. Psychol. 42, 260-269.

Levelt W. J. M. (1965) On binocular rivalry. Thesis, Leiden, Mouton, Den Haag.

Livshitz N. N. On the laws of binocular colour mixture. Dokl. Akad. Nauk SSSR 28, 429-432. 
Lu C. and Fender D. (1971) Short communication, Optical Society meeting. J. opt. Soc. Am. 61, 1567.

Over R. Long N. and Lovegrove W. (1973) Absence of binocular interaction between spatial and color attributes of visual stimuli. Percept. Psychophys. 13. 534-540.

Pettigrew J. D.. Nikara T. and Bishop P. O. (1968) Binocular interaction in single units in cat striate cortex. Simultancous stimulation by moving slits with receptive fields in correspondence. Expl Brain Res. 6, 391-410.

Pickford R. W. (1947) Binocular colour combinations, Nature. Lond. 159, 268-269.

Rochat G. F. (1922) Etude du mélange de rouge et de vert. Archs nierl. Phisiol. 7, 263-267.
Schrödinger E. (1926) In Mueller-Pouillets Lehrbuch der Physik, 2er Band. Vieweg. Braunschweig.

Thomas F. H., Dimmick F. L. and Luria S. M. (1961) A study of binocular color mixture Vision Res. 1, 108120.

Torgerson W. S. (1958) Theory and Methods of Scaling. Wilcy. New York.

Torgerson W. S. (1958) Theory and Methods of Scaling. Wiley. New York.

Walraven P. L. (1962) On the mcchanisms of color vision. Thesis, Utrecht. 